Journal of Animal and Veterinary Advances 10 (13): 1632-1637, 2011

ISSN: $1680-5593$

(C) Medwell Journals, 2011

\title{
The Reproduction Traits of Native Brown Trout (Salmo trutta macrostigma T., 1954), Turkey
}

\author{
M. Kocabas, M. Kayim, E. Can, F. Kutluyer and O. Aksu \\ Faculty of Fisheries, Tunceli University, 62000 Tunceli, Turkey
}

\begin{abstract}
Some key aspects of the reproductive strategy of the brown trout Salmo trutta macrostigma (T., 1954) inhabiting Uzungol stream, Trabzon including spawning season, age at sexual maturity, fecundity and egg size have been studied between January 2009 to May 2010. The ages of the captured fish ranged from $2-8$ years. Individuals were composed of $40.85 \%$ males and $37.80 \%$ females. The present investigation on the fecundity of S.t. macrostigma was carried out to estimate the average and range in the number of ova laid by individual female as well as to study the relationship of the fecundity with total length, total body weight. The mean value of absolute fecundity was $312.23 \pm 254.71$ (SD) eggs/female. The regression between egg number and fish size (total length and weight) was statistically significant $(\mathrm{p}<0.05)$.
\end{abstract}

Key words: Salmo trutta macrostigma, reproduction, gonadosomatic index, fecundity, body weight, Turkey

\section{INTRODUCTION}

Salmo trutta macrostigma is a salmonid species and has high economic value. The natural distribution area of S.t. macrostigma is the upper streams of rivers in North Africa, Europe, West Asia and Anatolia. Studies on fish reproductive biology is important to evaluate the reproductive potentials of the species (Duarte and Araujo, 2002) and it gives prerequisite information needed to plan a breeding programme so as to determine how many eggs would be spawned or stripped, the amount of rearing facilities required and the extent to which various culture equipment would be put to use (Eyo and Mgbenka, 1992). Despite the abundance of scientific literature on brown trout ecology and biology (Nicola and Almodovar, 2002; Arslan and Aras, 2007; Hao and Chen, 2008), there is scarce available information on reproductive biology of S.t. macrostigma populations. Kucuk was determinated spawning season of Salmo trutta macrostigma population in Koprucayi. Alp et al. (2003) reported that on the reproductive biology of S.t. macrostigma such as the spawning season, size at sexual maturity, fecundity and egg size in the Firniz stream, a tributary of the Ceyhan river which flows into the eastern Mediterranean sea. Demir et al. (2010) studied some reproductive features of brown trout (Salmo trutta macrostigma) and its larval development under culture conditions. No research has been made on S.t. macrostigma in Uzungol stream of the region of Trabzon, Turkey. The objectives of this study were to identify some important biological features, e.g., population growth pattern, gonadosomatic index and fecundity and to compare the findings on the spawning period with published data from other natural populations.

\section{MATERIALS AND METHODS}

The present study was carried out in Uzungol stream located at the latitude of $40^{\circ} 34^{\prime} \mathrm{N}$, longitude of $40^{\circ} 27^{\prime} \mathrm{E}$ and $40^{\circ} 37^{\prime} \mathrm{N}$, longitude of $40^{\circ} 16^{\prime} \mathrm{E}$ (Fig. 1). A total of

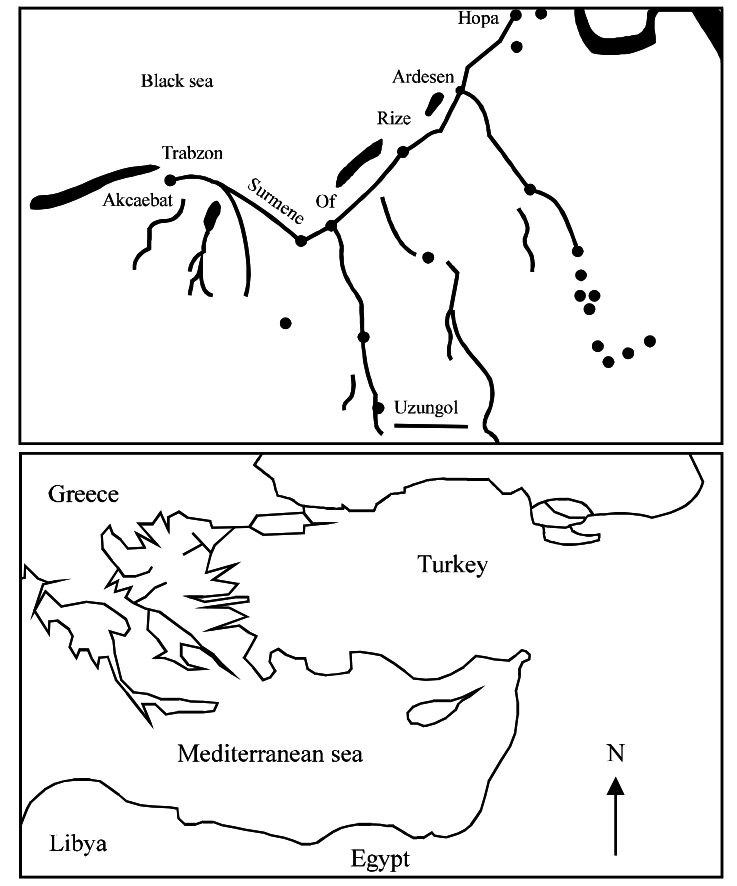

Fig. 1: The map of the study area

Corresponding Author: M. Kocabas, Faculty of Fisheries, Tunceli University, 62000 Tunceli, Turkey 
258 individuals of S.t. macrostigma caught monthly sampling sites in Uzungol stream between between March 2009 and May 2010, using by electrofishing. All fish caught were immediately preserved in a plastic barrel containing $4 \%$ formalin solution for later analysis in the laboratory. In the laboratory, Total Length (TL) was measured to the nearest $1 \mathrm{~mm}$ for all fish sampled. Total weight, weight of gonads and its subsamples were recorded with an electronic analytical balance to the nearest $0.01 \mathrm{~g}$. For the age determination opercula were used. All sampled fish were then dissected, gonads removed and weighed and sex determined visually or by microscope. The gonads were preserved in $4 \%$ formalin solution. The number of eggs was estimated by gravimetric method using five pieces removed from the ovary. They were then counted and mean value calculated from five sub-samples and weighed. The total number of eggs in each sub-sample ovary was determined. This value was proportional to the total ovary weight; the number of eggs (F1) for the subsample was estimated using the equation, F1 = (Gonad weight $\mathrm{x}$ number of eggs in the subsample)/subsample weight (Yeldan and Avsar, 2000). Later by taking the mean number of five sub-sample fecundities (F1-F5), the individual fecundity for each female fish was calculated:

$$
[\mathrm{F}=(\mathrm{F} 1+\mathrm{F} 2+\mathrm{F} 3+\mathrm{F} 4+\mathrm{F} 5) / 5]
$$

Relative fecundity index was calculated as:

Where:

$$
\mathrm{RF}=\mathrm{AF} / \mathrm{TW}
$$

$\mathrm{AF}=$ Absolute Fecundity

$\mathrm{TW}=$ Total Weight $($ Bagenal, 1978)

To examine the monthly changes in the gonads, the Gonadosomatic Index (GSI) was calculated for male and female specimens separately:

$$
\text { Gonadosomatic Index }(\text { GSI \% })=\frac{(\text { Gonad weight })}{(\text { Total body weight })} \times 100
$$

was calculated for each fish and all values were averaged for each sampling date (Gupta, 1975). Fork length, fecundity and body weight and fecundity relationships were determined from the equations:

Where:

$$
\mathrm{F}=\mathrm{q} \times \mathrm{FL}^{\mathrm{b}}, \mathrm{F}=\mathrm{q} \times \mathrm{W}_{\mathrm{B}}^{\mathrm{b}}
$$

$\mathrm{F}=$ Number of eggs (fecundity)

$\mathrm{FL}$ and $\mathrm{W}_{\mathrm{B}}=$ Fork length $(\mathrm{mm})$ and body weight $(\mathrm{g})$, respectively where, $a$ and $b$ are constant parameters in linear regression analysis and $\mathrm{q}=\mathrm{e}^{\mathrm{a}}$. Fecundity was estimated according to Bagenal and Braum (1978).

The egg shapes were round and slightly hard when diameters were being measured. The mean fecundities and mean egg diameters for individuals were recorded by age, length and weight of each examined female fish.

Statistic analysis: Comparison of GSI between months was carried out by Analysis of Variance (ANOVA). An Analysis of Co-Variance (ANCOVA) was performed to test significance differences in weight-length relationships and GSI values between the sexes. The overall sex ratio was assessed using Chi-square $\left(\chi^{2}\right)$ test. Statistical analyses were performed with SPSS 14.0 software package and a significant level of 0.05 was accepted.

\section{RESULTS AND DISCUSSION}

Sex ratio and length-weight relationships: A total of 258 samples of S.t. macrostigma with observable gonads were used for the study. The trout caught ranged in size from $9.0-37.8 \mathrm{~cm}$ TL and in total weight from $7.29-445.0 \mathrm{~g}$. Of the 258 specimens collected, 134 (40.85\%) were identified as males, ranging from $9.0-37.8 \mathrm{~cm}$ and $7.29-445.0 \mathrm{~g}$ while $124(37.80 \%)$ were females ranging from 9.5-30.4 cm and 9.38-226.24 g (Fig. 2). This gives a male/female ratio of 1:0.92 in favour of the females Chi-square analysis showed significant differences between populations of this species throughout its range distribution $\left(\chi^{2}=25.924, \mathrm{df}=8, \mathrm{p}<0.01\right)$. Length-weight relationships calculated by using the lengths and weights of the 258 S.t. macrostigma specimens were found as $W=0.0115 \mathrm{x}^{2.9494}$ for males and $\mathrm{W}=0.0176 \mathrm{x}^{2.788}$ for females (Fig. 3). The b value of males was higher than that of females. The correlation coefficients of these

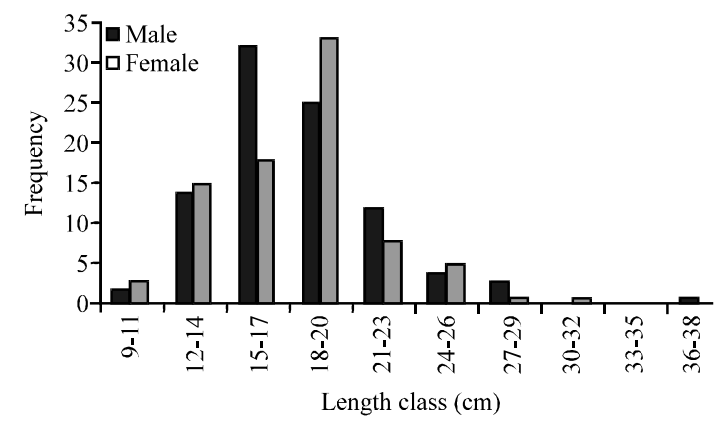

Fig. 2: Total length $(\mathrm{cm})$ and weight $(\mathrm{g})$ frequency of males and females of trout, S.t. macrostigma 


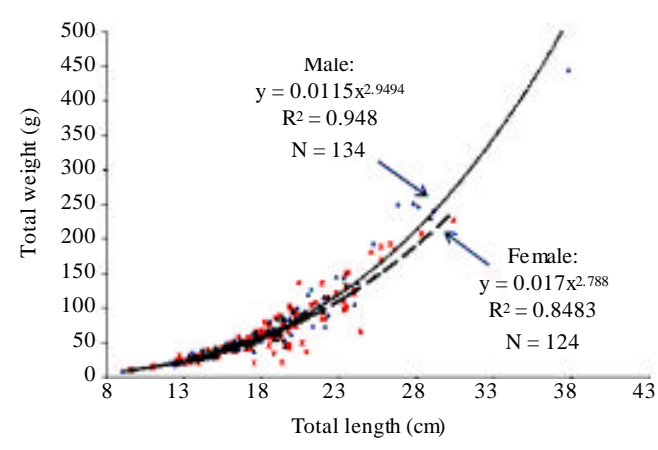

Fig. 3: Length-weight relationship of S.t. macrostigma in the Uzungol stream

Table 1: The age and sex composition of S.t. macrostigma in Uzungol stream $(\mathrm{N}=$ No. of fish)

\begin{tabular}{lrrrrrr}
\hline & Male & \multicolumn{3}{c}{ Female } & \multicolumn{2}{c}{ Male+Female } \\
& \multicolumn{1}{c}{ Age } & N (\%) & \multicolumn{1}{c}{ N } & N (\%) & \multicolumn{1}{c}{ N } & N (\%) \\
\hline 2 & 22 & 16.42 & 7 & 5.65 & 29 & 11.24 \\
3 & 57 & 42.54 & 55 & 44.35 & 112 & 43.41 \\
4 & 38 & 28.36 & 47 & 37.90 & 85 & 32.95 \\
5 & 10 & 7.46 & 10 & 8.06 & 20 & 7.75 \\
6 & 4 & 2.99 & 5 & 4.03 & 9 & 3.49 \\
7 & 2 & 1.49 & - & - & 2 & 0.78 \\
8 & 1 & 0.75 & - & - & 1 & 0.39 \\
Total & 134 & 100.00 & 124 & 100.00 & 258 & 100.00 \\
\hline
\end{tabular}

relationships for males $(r=0.984)$ and females $(r=0.8483)$ were always close to one and significant $(\mathrm{p}<0.05)$. Significant differences were obtained from the statistical comparison of length-weightrelationships between males and females (ANCOVA, $\mathrm{F}=7.366, \mathrm{p}<0.05$ ).

Age and length at 1st maturity: Age was determined from 258 specimens. Seven age groups (2-8) were identified in both sexes. Males of age groups ranged from 2-8 while the ages of female fish ranged from 3-6 years. The age and sex distribution of specimens caught during this study is shown Table 1. The most samples was in the 3rd age group accounting for $>43.41 \%$ of the total number aged. First spawning was at age 3 for females and age 2 for males. The smallest mature females and males were in the $11-18 \mathrm{~cm}$ length class (the smallest mature female was $11.9 \mathrm{~cm}$, the smallest mature male was $17.5 \mathrm{~cm}$ ).

Reproduction period and Gonadosomatic Index (GSI): The GSI in 258 brown trout ranged from 0.33-7.81. Gonadosomatic index varied from $0.63-7.81$ with a mean index of $3.27 \pm 2.36$ in female fish and from $0.33-1.97$ with mean index of $1.11 \pm 0.59 \mathrm{in}$ male fish. Mean ovarian weight was $9.91 \pm 81.74 \mathrm{~g}$. The lowest monthly GSI among female fish was on April while the highest was 7.81 at the beginning of November. Similarly, the lowest monthly GSI in males was on March and the highest in December (Fig. 4). Monthly GSI values were significantly ( $F=20.157$, $\mathrm{p}<0.05$ ).

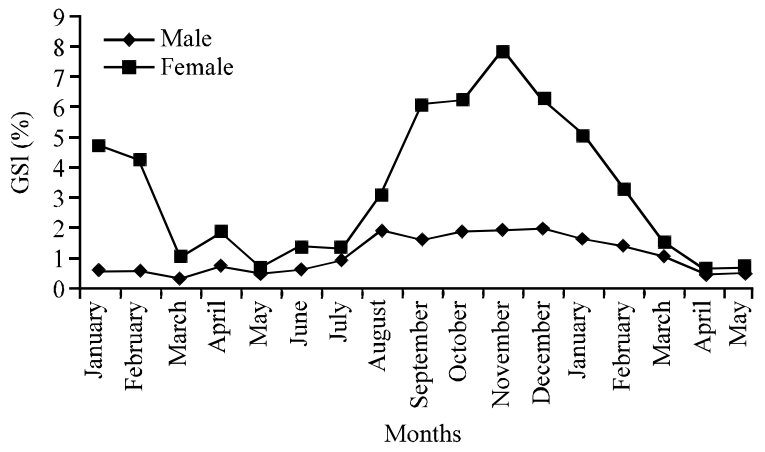

Fig. 4: Monthly variations in the GSI of S.t. macrostigma

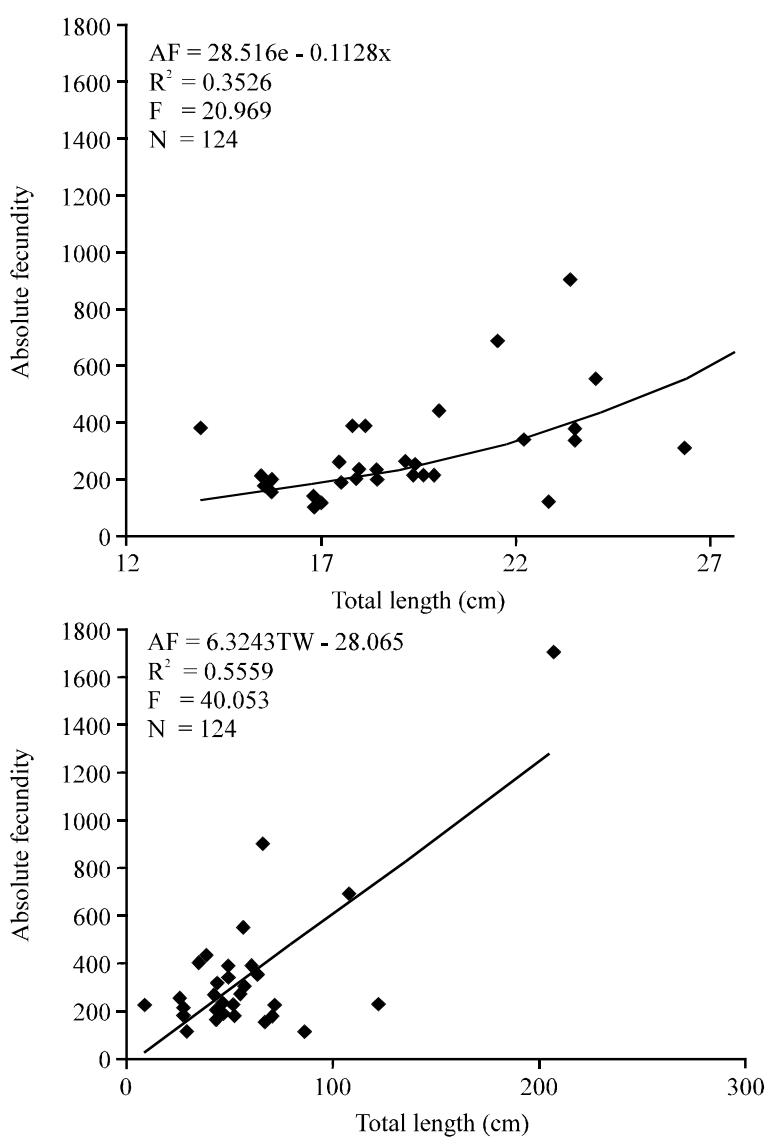

Fig. 5: Relationship between egg number and fish total length $(\mathrm{mm})$ and total weight $(\mathrm{g})$ of female S.t. macrostigma in the Uzungol stream

Fecundity: To determine egg productivity, the total egg number in the ovaries of 124 female S.t. macrostigma was used. The mean value of absolute fecundity was $312.23 \pm 254.71$ (SD) eggs/female. The regression between egg number and fish size (total length and weight) was statistically significant $(\mathrm{p}<0.05$ ) (Fig. 5). The mean egg weight of S.t. macrostigma was $0.055 \pm 0.011 \mathrm{mg}$ (SD). The 

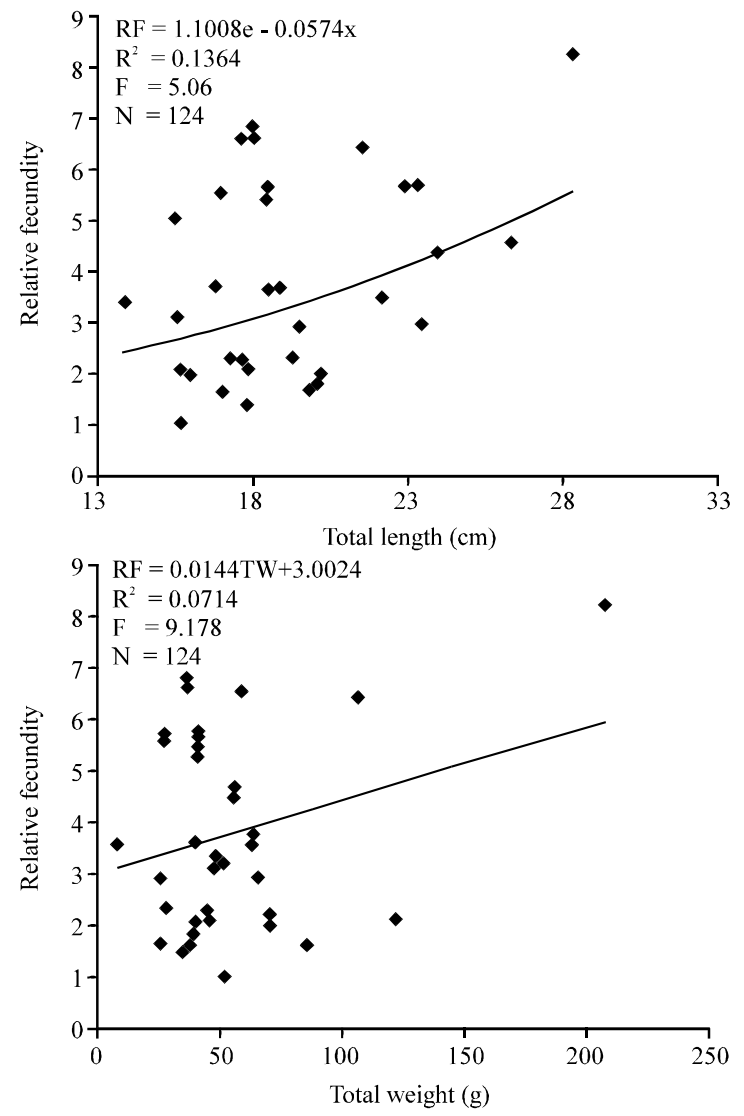

Fig. 6: Relationship between relative fecundity and fish total length (mm) and total weight $(\mathrm{g})$ of female S.t. macrostigma in the Uzungol stream

mean egg diameter was between 0.32 and $0.51 \mathrm{~mm}$ with a mean index of $0.39 \pm 0.03$ (SD) in various age groups. Fecundity relative to total weight fluctuated from $1.05-8.22$ eggs X g with a mean value of $4.28 \pm 2.98$. The relationship of relative fecundity with fish size (total length and total weight) was found to be statistically significant $(\mathrm{p}<0.05)$ (Fig. 6).

The sex ratio of $S$. trutta was reported as 0.54:1 in the Tekederesi stream (Yuksel and Kocaman, 1998) and 1:0.41 in the Catak stream (Cetinkaya, 1999). Alp et al. (2003) reported that the sex ratio of S.t. macrostigma in the Firniz stream was $0.67: 1$. In the study, ratio of females of S.t. macrostigma in the Uzungol stream is similar to recorded by Cetinkaya (1999). Contrary to finding by other studies in present study, numbers of males in trout populations were more abundant than females. In the study, minimum size at 1 st maturity of S.t. macrostigma in living Uzungol stream was determinated that the smallest mature female was $11.9 \mathrm{~cm}$, the smallest mature male was $17.5 \mathrm{~cm}$. Cetinkaya (1999) reported that the smallest mature lengths were $16-17 \mathrm{~cm}$ in the Catak stream. Yildirim reported the smallest mature fish length was $14.1 \mathrm{~cm}$ in the Barhal reservoir. Yanar recorded that the smallest length of mature fish was reported as $15.7 \mathrm{~cm}$ in the Hodacu stream.

Arslan and Aras (2007) reported that male and female brown trout attained maturity at the age of 14.1 and $17.2 \mathrm{~cm}$ in the Anuri stream and were 14.0 and $17.3 \mathrm{~cm}$ length in the Cenker stream. Alp et al. (2003) determinated that the smallest mature male and female fishes were 17.4 and $17.8 \mathrm{~cm}$, respectively. The minimum size at 1 st maturity for brown trout were reported as 10.5-11.0 in Spain (Lobon-Cervia et al., 1997). Males of minimum size at 1st maturity of brown trout in the Uzungol stream is similar to recorded by Alp et al. (2003) and Arslan and Aras (2007) but females of minimum size at first maturity show similarity with recorded by Lobon-Cervia et al. (1997).

Geldiay and Balik reported that age at sexual maturity of brown trout living in Turkish waters in age groups were as 2-4. Crisp et al. (1974, 1990), Cetinkaya (1999) and Alp et al. (2003) reported age at sexual maturity ranges of $2-3,3-4,4,3,3-4$ and $2-3$ in their $S$. trutta populations, respectively. In this study, the observed age at first maturity male and female fishes were similar to reported by Alp et al. (2003) and Crisp et al. (1974). The observed range of eggs weights $34-86 \mathrm{mg}$ was different from that of 11-71 $\mathrm{mg}$ reported by Alp et al. (2003) in Firniz stream in Turkey and that of 53-63 and 65-76 mg found by Crisp et al. (1974) and Crisp (1990) at Northern England.

Kucuk and Karatas determined that spawning of S. trutta in Koprucay stream and Gokpinar stream took place in December, January and November, respectively. November and December in some streams such as the Kapsitre, Caglayan, Firtina, Iyidere and Solakli streams in the Eastern Black sea region and September and October in the Anuri and Cenker stream (Arslan and Aras, 2007). Alp et al. (2003) reported that the spawning period of S.t. macrostigma in the Firniz stream was from November to February. Gortazar et al. (2007) reported spawning period extended from December to mid-April and the maximum reproductive activity was in February. In this study, the spawning period was from November to January. Consistent with results of previous studies, spawning periodicity of S.t. macrostigma indicate more or less a similar time period for spawning. In $S$. trutta, fecundity increased with increasing fish size (length and weight) as also observed by Alp et al. (2003), Arslan and Aras (2007) and Nicola and Almodovar (2002). Lobon-Cervia et al. (1997) indicated that trout length was the major determinant of fecundity. The present study confirmed that fecundity was significantly related to both 
fish length and weight. Geldiay and Balik reported that the number of eggs produced by brown trout living in Turkish waters as $2000-5000 \mathrm{~kg}^{-1}$. Cetinkaya (1999), Alp et al. (2003) and Arslan and Aras (2007) reported the number of eggs kg-1 of fish weight ranges of 3230,3113 , $2810,2340,2810,3099$ and 2730-3225 in their S. trutta populations, respectively. In the study, it was determinated as $3122 \mathrm{~kg}^{-1}$. We obtained a similar result from the other brown trout populations from fresh waters. Consequently, fecundity increased with increasing fish size (length and weight).

The smallest mature females and males were in the $11-18 \mathrm{~cm}$ length class and age at $1 \mathrm{st}$ maturity male and female fishes were 2 and 3 in Uzungol stream. S.t. macrostigma inland waters has been under threat because of illegal fishing, overfishing and other environmental changes. Hence, closed and less intense would help conservation of the natural stock of the fish by allowing the fish to breed at least once in their lifetime. It is recommended that these problems should be taken into consideration regarding the restocking of streams.

\section{CONCLUSION}

Relative fecundity which is calculated as the number of eggs per unit, the average relative fecundity was $4.28 \pm 2.98(\mathrm{SD})$ eggs $\mathrm{X} \mathrm{g}^{-1}$. Gonado-somatic index varied from $0.08-21.35$ with a mean index of $2.17 \pm 3.51$ (SD) in female fish and from 0.07-3.20 with mean index of $0.92 \pm 0.87$ (SD) in male fish. The mean egg diameter was between 0.32 and $0.51 \mathrm{~mm}$ with a mean index of $0.39 \pm 0.03$ (SD) in various age groups. Further researches about the brown trout population in the Uzungol river should be conducted on issues such as artificial reproduction, culture, conservation, management and restocking.

\section{ACKNOWLEDGEMENTS}

The researchers would like to express their special thanks to Turkish Ministry of Environment and ForestryEnvironmental Protection Agency for Special Areas (EPASA) for financial support. We should also like to thank Murat Erdem Guzel, Zeynep Colak, Osman Sinan and Murat Fidan for kindly helping.

\section{REFERENCES}

Alp, A., C. Kara and H.M. Buyukcapar, 2003. Reproductive biology of brown trout, Salmo trutta macrostigma Dumeril, 1858 in a triburaty of the Ceyhan River which flows into the Eastern Mediterranean Sea. J. Applied Ichthyol., 19: 346-351.
Arslan, M. and N.M. Aras, 2007. Structure and reproductive characteristics of two brown trout (Salmo trutta) populations in the Coruh River Basin, North-Eastern Anatolia, Turkey. Turk. J. Zool., 31: 185-192.

Bagenal, T.B. and E. Braum, 1978. Eggs and Early Life History. In: Methods for Assessment of Fish Production in Fresh Water, Bagenal, T.B. (Ed.). Blackwell Scientific Publications, Oxford, pp: 165-201.

Bagenal, T.B., 1978. Methods for Assessment of Fish Production in Freshwaters. 3rd Edn., Blackwell Scientific Publication, Oxford, London, pp: 365.

Cetinkaya, O., 1999. Investigations of some biological proporties of brown trout (Salmo trutta macrostigma Dum., 1858) Living the Catak Stream (Tigris River. Turkey). Istanbul Univ. J. Aquatic Prod., 9: 111-122.

Crisp, D.T., R.H.K. Mann and J.C. McCormack, 1974. The populations of fish at Crow Green, upper Teesdale, before impoundment. J. Applied Ecol., 11: 969-996.

Crisp, D.T., R.H.K. Mann, P.R. Cubby and S. Robson, 1990. Effects ofimpoun dment upon trout (Salmo trutta) in the basin of Cow Green reservoir. J. Applied Ecol., 27: 1020-1041.

Demir, O., I. Gulle, E. Gumus, F. Kucuk, A. Gunluand K. Kepenek, 2010. Some reproductive features of brown trout (Salmo trutta macrostigma Dumeril, 1858) and its larval development under culture conditions. Pak. Vet. J., 30: 223-226.

Duarte, F. and F.G. Araujo, 2002. Fecundity of the Hypostomus affinis (Siluriformes, Loricariidae) in the Lajes Reservoir, Rio de Janeiro, Brazil. Rev. Biol., 50: 193-197.

Eyo, J.E. and B.O. Mgbenka, 1992. Aspects of the biology of Clarias gariepinus in Anambra River basin I: Oocyte diameter, fecundity and sex ratio. J. Agric, Sci. Technol., 2: 47-51.

Gortazar, J., D.G. de Jalon, C. Alonso-Gonzalez, P. Vizcaino, D. Baeza and M. Marchamalo, 2007. Spawning period of a southern brown trout population in a highly unpredictable stream. Ecol. Freshwater Fish, 16: 515-527.

Gupta, S., 1975. The development of carp gonads in warm water aquaria. J. Fish. Biol., 7: 775-782.

Hao, F. and Y. Chen, 2008. The reproductive traits of brown trout (Salmo trutta fario L.) from the Yadong River, Tibet. Environ. Biol. Fish., 1: 89-96. 
Lobon-Cervia, J., C. Utrilla, P. Rincon and F. Amezcua, 1997. Environmentally induced spatio-temporal variations in the fecundity of brown trout Salmo trutta L.: trade-offs between egg size and number. Freshwater Biol., 38: 277-288.

Nicola, G.G. and A. Almodovar, 2002. Reproductive traits of stream dwelling brown trout Salmo trutta in contrasting neighboring rivers of central Spain. Freshwater Biol., 47: 1353-1365.
Yeldan, H. and D. Avsar, 2000. A preliminary study on the reproduction of the rabbitfish (Siganus rivulatus (Forsskal, 1775)) in northeastern Mediterranean. Turk. J. Zool., 24: 173-182.

Yuksel, A.Y. and E.M. Kocaman, 1998. Some properties of brown trout (S. t. macrostigma Dumeril 1858) in Tekederesi (Erzurum), III. Proceedings of the Fisheries Symposium of East Anatolia, (FSEA'98), Erzurum, pp: $361-372$. 